\title{
A comparison of a fluorescent antibody technique with a cultural method in the detection of infections with Shigella sonnei
}

\author{
C. E. D. TAYLOR, G. V. HEIMER, D. J. LEA, AND A. J. H. TOMLINSON \\ From the Central Public Health Laboratory, Colindale Avenue, London, and the \\ Bacteriological Laboratory (P.H.L.S.), County Hall, London
}

SYNOPSIS A comparison has been made of a fluorescent antibody technique with a cultural method for the detection of Sh. sonnei in faeces. The two methods were in agreement in $73 \%$ of the 394 specimens examined; $57(14.5 \%)$ specimens were positive by culture only; $52(13.2 \%)$ specimens gave positive results by fluorescence microscopy which were not confirmed by culture. Most of the latter are thought to be 'false positive' results.

The value and usefulness of fluorescence microscopy in the diagnosis of Sonne dysentery is discussed.

Fluorescent antibody techniques as an aid in the diagnosis of infectious diseases have been critically reviewed by Cherry, Goldman, and Carski (1960) and by Smith, Metzger, and Hoggan (1962). The techniques have been widely explored in respect of a great many different microorganisms including bacteria (Moody and Winter, 1959; Metzger and Smith, 1960), fungi (Gordon, 1958), viruses (Liu, 1956; Biegeleisen, Scott, and Lewis, 1959; Kalter, Hatch, and Ajello, 1959), and protozoa (McEntegart, Chadwick, and Nairn, 1958; Carver and Goldman, 1959), but many accounts concern work with cultures of organisms or material derived from experimentally infected animals. The use of the technique in the rapid detection and identification of microorganisms in material obtained directly from patients does not appear to have been adequately investigated. Moreover, other workers, for the most part, have not sought to compare fluorescent antibody techniques with isolation of pathogenic microorganisms by means of a highly sensitive cultural procedure. It seemed desirable, therefore, to make such a comparison as part of a larger attempt to evaluate the sensitivity and specificity of fluorescent antibody techniques. Sonne dysentery was selected for this purpose since there was plenty of material with which to make a comparison, and, provided care is taken in the preparation of deoxycholate citrate agar, the isolation of Shigella sonnei in

Received for publication 6 November 1963. culture using this medium can be extremely reliable. Little has been recorded concerning the use of the fluorescent antibody technique in the diagnosis of Sonne dysentery, although Cherry, Thomason, Pomales-Lebrón, and Ewing (1961) tried a fluorescein-conjugated Sh. sonnei antiserum while endeavouring to identify Esch. coli in faecal smears.

\section{MATERIALS AND METHODS}

These are described in considerable detail in order to allow others to assess the comparative value of the two methods.

PREPARATION OF CULTURE MEDIUM The deoxycholate citrate agar medium was made up as follows:

\section{Lactose agar base}

Yeastrel ........................

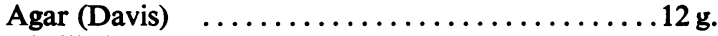

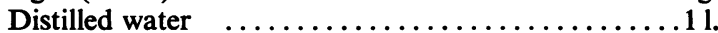

These were autoclaved at $115^{\circ} \mathrm{C}$. for five minutes to dissolve the constituents. While hot, were added peptone (Evans), $5 \mathrm{~g}$., and lactose, $10 \mathrm{~g}$. After shaking to dissolve these ingredients, the $p \mathrm{H}$ was adjusted to $8 \cdot 0$. The medium was bottled in $500 \mathrm{ml}$. amounts and sterilized at $115^{\circ} \mathrm{C}$. for 10 minutes.

\section{Solution $A$}

Trisodium citrate $\mathrm{Na}_{3} \mathrm{C}_{6} \mathrm{H}_{5} \mathrm{O}_{7} \cdot 2 \mathrm{H}_{2} \mathrm{O}$ (Analar) . . . . $17 \mathrm{~g}$. Sodium thiosulphate $\mathrm{Na}_{2} \mathrm{~S}_{2} \mathrm{O}_{3} \cdot 5 \mathrm{H}_{2} \mathrm{O}$ (Analar) ......17 g. Ferric citrate scales $\mathrm{FeC}_{6} \mathrm{H}_{5} \mathrm{O}_{7} \cdot 5 \mathrm{H}_{2} \mathrm{O}$ (B.D.H.) . . . . 2 g. Sterile distilled water $\ldots \ldots \ldots \ldots \ldots \ldots \ldots 100 \mathrm{ml}$.

The salts were added to the cold sterile water and left to dissolve at room temperature for two to three days. 
Solution B

Sodium deoxycholate $\ldots \ldots \ldots \ldots \ldots \ldots \ldots \ldots$ g. Sterile distilled water $\ldots \ldots \ldots \ldots \ldots \ldots \ldots 100 \mathrm{ml}$.

To prepare the complete medium, $500 \mathrm{ml}$. of agar base was melted. The $p H$ was checked and, when necessary, adjusted to $7 \cdot 6$. Then $25 \mathrm{ml}$. of solution $\mathrm{A}, 25 \mathrm{ml}$. of solution $B$, and $0.8 \mathrm{ml}$. of $1 \%$ neutral red were added and the complete medium, while still hot, was poured into plastic Petri dishes $9: \mathrm{cm}$. in diameter to a depth of approximately $7 \mathrm{~mm}$. The final $p H$ of the medium in the Petri dish was 7·3.

Samples of sodium deoxycholate appear to vary in the amount of alkali they contain, and it may be necessary to add more alkali to solution $\mathrm{B}$ (up to $10 \mathrm{ml}$. of $\mathrm{N} \mathrm{NaOH}$ per $100 \mathrm{ml}$. may be needed) in order that the $p \mathrm{H}$ of the final medium shall be correct.

The formula for this medium differs from the original one for Leifson's medium, in that Yeastrel has been substituted for Lab-Lemco. This change was brought about by the increased cost of Lab-Lemco, and after extensive comparative tests had shown that the medium containing Yeastrel, although darker in colour and perhaps slightly less inhibitory than the original, was in all other respects identical with it.

TESTING OF DEOXYCHOLATE CITRATE AGAR MEDIUM The most important, and the most variable, of the ingredients in this medium is sodium deoxycholate. It is essential, therefore, in order to obtain a medium with the maximum sensitivity and selectivity, that each batch of this chemical be tested before use. Samples were obtained from a number of manufacturers and the final medium prepared with each of them. A single batch of agar base was used and the media were finally poured in standard volumes into plastic Petri dishes.

Specimens of faeces were selected for testing the different preparations of medium. Some specimens were selected because they were known to contain adequate numbers of Sh. sonnei, Sh. flexneri, Salm. typhi, or other salmonellae. Additional specimens were selected because they were known to contain large numbers of viable coliforms the growth of which should be inhibited on deoxycholate citrate agar. Usually about 12 selected specimens of faeces sufficed to carry out these tests. So far as possible in investigations of this kind, stock cultures of organisms should be avoided since they may have undergone some antigenic change and they may have become adapted to growth in laboratory culture media in general and on deoxycholate citrate agar in particular.

From each specimen of faeces, an approximate $10 \%$ suspension was made in quarter strength Ringer solution and five serial ten-fold dilutions were prepared from this suspension. Surface plate counts were carried out, in duplicate, with each faecal suspension. All six dilutions were tested on each of the different batches of sodium deoxycholate, and, in addition, on MacConkey agar which is a less inhibitory medium. After overnight incubation, the plates were examined, the identity of the non-lactose fermenting colonies checked by slide agglutination, and the numbers of the different organisms recorded.
The most suitable of the samples of sodium deoxycholate was selected on the following basis: 1 It must not inhibit in any way the growth of intestinal pathogens when compared with the less inhibitory MacConkey medium. 2 It must give the maximum inhibition of non-pathogens. 3 The colonies of pathogens must be of reasonable size after 16 to 18 hours' incubation and must give good slide agglutination reactions. 4 Cost.

This method of comparing media, by means of viable counts from selected specimens of faeces, is preferable to replicate plating of unselected material on the various $\vec{O}$ media. Several hundred specimens may need to be examined by the latter method to detect with certainty even quite gross differences between media.

ROUTINE METHOD FOR ISOLATION OF SH. SONNEI FROM $\vec{v}$ FAECES As large a portion of each specimen of faeces as $\omega$ could conveniently be picked up on the end of a sterile $\mathrm{N}$ wooden applicator stick was plated on deoxycholate $\mathrm{F}$ citrate agar and a similar amount was inoculated into 을 Selenite F broth. Growth from the Selenite medium was subcultured after overnight incubation on to deoxycholate citrate agar.

Colonies of Sh. sonnei were identified by their appearance and by slide agglutination. Only a very small number of additional positive results was obtained after enrichment in Selenite medium.

These cultural methods enabled Sh. sonnei to be isolated when it was present in the faeces in numbers of the order of 100 to 10,000 per gram, depending on the numbers of non-pathogenic organisms growing on the deoxycholate citrate agar.

PREPARATION OF FLUORESCENT CONJUGATES Fractions of two antisera, one prepared against a phase 1 (N.C.T.C. No. 9773) and the other prepared against a phase 2 (N.C.T.C. No. 8219) strain of Sh. sonnei, having agglutinating titres of 1 in 2,000 and 1 in 10,000 respectively, were conjugated with fluorescein isothiocyanate. (Both sera were kindly supplied by Dr. C. M. Patricia Bradstreet, Director of the Standards Laboratory for Serological Reagents, Colindale.)

Each antiserum was dialysed at room temperature against an equal volume of saturated ammonium sulphate solution for $\mathbf{2 4}$ hours. The precipitate containing the antibody was washed once with $50 \%$ saturated ammonium sulphate, dissolved in a small volume of normal saline, and dialysed at $4^{\circ} \mathrm{C}$. against normal saline which was changed frequently until no further ammonium sulphate was detectable in the dialysate. This took about two days.

The resulting solution was clarified by filtration and the protein content estimated by ultraviolet spectrophotometry. (In a $1 \mathrm{~cm}$. cell an optical density of 1.24 at $280 \mathrm{~m} \mu$ is equivalent to $1 \mathrm{mg}$. protein per $\mathrm{ml}$.) The test solution was $0.1 \mathrm{ml}$. antiserum fraction in $2.9 \mathrm{ml}$. diluent.

A $4 \%$ dispersion of fluorescein isothiocyanate ${ }^{1}$ on acid-washed diatomaceous earth (Celite) ${ }^{2}$ was prepared with anhydrous acetone as the solvent (Rinderknecht,

${ }^{1}$ Obtained from British Drug Houses Ltd., Poole, Dorset, England. ${ }^{2}$ Obtained from L. Light \& Co. Ltd., Colnbrook, Bucks., England. N N 
1960). This dispersion was used to prepare conjugates containing varying proportions of fluorescein as measured by spectrophotometry at $495 \mathrm{~m} \mu$ (Goldstein, Slizys, and Chase, 1961).

Labelling with $30 \mathrm{mg}$. fluorescein isothiocyanate per gram of protein gave a final preparation with a fluorescein-protein ratio of $0.39: 1$ as measured by optical densities at $495 \mathrm{~m} \mu$ and $280 \mathrm{~m} \mu$ respectively. The amount of fluorescein isothiocyanate required to give this ratio depends upon the particular dispersion and the batch of fluorescein isothiocyanate used in its preparation. This degree of labelling gave a product which did not need absorption with tissue powders before use at the highest effective dilution. Products with lower fluorescein contents were not sufficiently visible in microscopic preparations.

The technique of conjugation was as follows:

The antiserum fraction was mixed with $0.5 \mathrm{M}$ sodium carbonate-bicarbonate buffer $(p \mathrm{H} \mathrm{9.0)}$ to give a final protein concentration of 15 to $20 \mathrm{mg}$./ml. Fluorescein isothiocyanate dispersion was added and the mixture stirred for $\mathbf{3 0}$ minutes. The solution was centrifuged free of diatomaceous earth and applied to a column of Sephadex G100 previously equilibrated for 24 hours with phosphate buffered saline $(p \mathrm{H} \mathrm{8.0)}$ ). The surface of the column was protected from disturbance by a disc cut from coarse glass wool fibres. A column size of $7 \times 1 \mathrm{~cm}$. was sufficient for the separation of $2 \mathrm{ml}$. of conjugate.

The labelled protein mixed with free fluorescein was allowed to enter the column by draining buffer from the bottom; portions of buffer were then added to the top of the column, draining slowly. The orange-coloured labelled protein eluted first, leaving the free fluorescein as a discrete band in the column, which was discarded. The concentration of protein in the end product was little lower than that in the starting material. The final preparation was filtered through an Oxoid cellulose acetate membrane. Each conjugate was titrated with the strain of Sh. sonnei used for making the antiserum in order to determine the highest dilution which gave satisfactory fluorescence. Each was tested also for specificity against two other shigella strains and against an organism related antigenically to Sh. sonnei, known as C.27. With conjugates used at their highest effective dilutions, cross-reactions with these organisms were not found.

FLUORESCENCE MICROSCOPY A $3 \mathrm{~mm}$. loopful of material from each specimen of faeces was mixed in a loopful of phosphate-buffered saline $(p \mathrm{H} 8.0)$ and spread within an etched rectangle on a thin microscope slide. Preparations of four specimens were made per slide. After drying at $37^{\circ} \mathrm{C}$., the smears were fixed in methanol for 10 minutes and then allowed to dry. One drop of a mixture of Sh. sonnei phase 1 and 2 serum conjugates diluted to their highest effective dilution $(1 / 20)$ in phosphate-buffered saline was spread over each smear, and the slide placed in a Petri dish containing moistened filter paper for 20 minutes at $37^{\circ} \mathrm{C}$. After washing in three changes of phosphate-buffered saline the preparations were mounted in Elvanol ${ }^{3}$ (Rodriguez and Deinhardt,
1960) and covered with a No.1 2 in. $\times 7 / 8$ in. glass cover-slip.

Preparations were examined in a darkened cabinet by means of a Watson Bactil microscope fitted with a dark ground condenser. Carl Zeiss fluorescence-free immersion oil $^{4}$ was used. The light source was a 250 w. ME/D mercury vapour compact source lamp. ${ }^{5}$ The excitation filter was an OX1 $2 \mathrm{~mm}$. thick Chance Pilkington glass filter. Within the body of the microscope was placed an 805 Q Ilford colourless gelatine ultraviolet barrier filter.

Twenty fields of each preparation were scanned systematically and specimens classified as follows:

$$
\begin{aligned}
++++ & =>20 \text { fluorescing organisms per field } \\
+++ & =11-20 \text { fluorescing organisms per field } \\
++ & =1-10 \text { fluorescing organisms per field } \\
+ & =<1 \text { fluorescing organism per field } \\
0 & =0 \text { fluorescing organisms per field }
\end{aligned}
$$

It should be emphasized that, for the purposes of this investigation, any specimen found to contain fluorescing organisms was regarded as positive, irrespective of the morphology of the organisms, because it was thought that in some specimens of faeces pleomorphism might well occur. Furthermore, little attention was paid to degrees of fluorescence, all fluorescence being regarded as positive.

\section{RESULTS}

To obviate the possibility of observer bias, the cultural work was carried out in a laboratory some 10 miles distant from the laboratory where the fluorescence microscopy was done. Results were exchanged when the examinations were completed.

Batches of faeces were selected for examination by fluorescence microscopy from the material submitted for bacteriological examination, so that each batch included some specimens from which Sh. sonnei had been isolated in varying numbers, and others from which Sh. sonnei had not been isolated. The specimens were kept at room temperature for 24 to 48 hours pending the results of cultural examination. Results obtained with 320 specimens of faeces are given in Table $I$.

A further series of specimens from 74 patients with diarrhoea was selected for microscopic examination solely on the appearance of each specimen. The results of culture and fluorescence microscopy obtained with these specimens are given in Table II.

A number of specimens, 43 in Table $I$ and nine in Table II, negative on culture but positive by fluorescence microscopy, have been provisionally

3Obtained from Brown \& Forth Ltd., 83-117 Euston Road, London, England.

Obtained from Degenhardt \& Co. Ltd., 20-22 Mortimer Street, London, England.

sObtained from Cooke Troughton \& Simms Ltd., Broadway Court, Westminster, London, England. 
TABLE I

COMPARISON OF FLUORESCENT ANTIBODY TECHNIQUE WITH CULTURAL METHOD IN ROUTINE SPECIMENS

\begin{tabular}{lllllll}
$\begin{array}{l}\text { Fluorescent } \\
\text { Culture }\end{array}$ & + & $\begin{array}{l}\text { Fluorescent } \\
\text { Culture }\end{array}$ & - & $\begin{array}{l}\text { Fluorescent } \\
\text { Culture }\end{array}$ & $+\quad \begin{array}{l}\text { Fluorescent } \\
\text { Culture }\end{array}$ & $\begin{array}{l}\text { Total } \\
+\end{array}$ \\
\hline $69(21.7 \%)$ & $158(49.3 \%)$ & & $43(13.4 \%)$ & $50 \quad(15.6 \%)$
\end{tabular}

TABLE II

COMPARISON OF FLUORESCENT ANTIBODY TECHNIQUE WITH CULTURAL METHOD IN CASES OF DIARRHOEA

\begin{tabular}{lllllll}
$\begin{array}{l}\text { Fluorescent } \\
\text { Culture }\end{array}$ & + & $\begin{array}{l}\text { Fluorescent } \\
\text { Culture }\end{array}$ & - & $\begin{array}{l}\text { Fluorescent } \\
\text { Culture }\end{array}$ & + & $\begin{array}{l}\text { Fluorescent } \\
\text { Culture }\end{array}$ \\
\hline $29(39 \%)$ & + & $29(39 \%)$ & $9(12 \%)$ & $7(10 \%)$ & $\begin{array}{l}\text { Total } \\
+\end{array}$
\end{tabular}

regarded as 'false positives', and will be discussed later. Many of these specimens were cultured a second time but only once was $S h$. sonnei isolated from a specimen which had originally given a negative result on culture.

It has been estimated that the technique used for fluorescence microscopy as described here is unlikely to detect organisms in a concentration of less than 1,000,000 per gram of faeces, so it is not surprising to find that the cultural method produced some positive results which were not detected by fluorescence microscopy (Table III).

\section{TABLE III}

COMPARISON OF FLUORESCENT ANTIBODY TECHNIQUE WITH CULTURAL METHOD IN CASES OF SONNE DYSENTERY

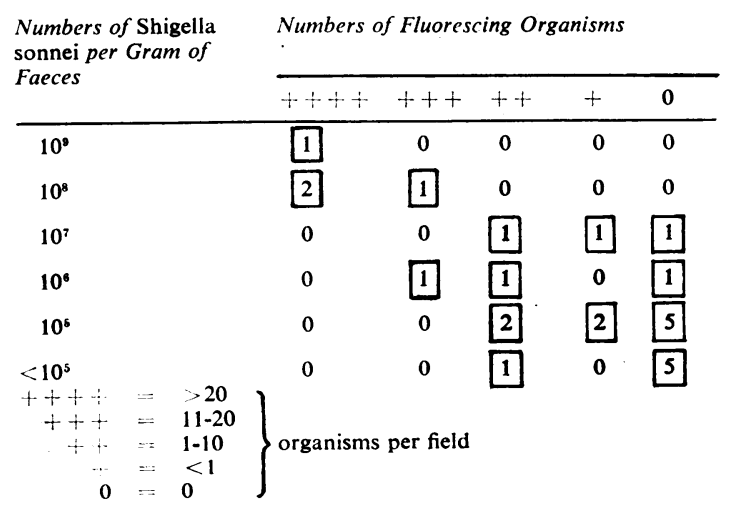

In Table IV it can be seen that there were 41 routine specimens of faeces in which large numbers $(+++$ and ++++$)$ of fluorescing organisms were observed and that Sh. sonnei was isolated from 33 of these. On the other hand, there were 71 specimens in which there were smaller numbers $(+$ and ++$)$ of fluorescing organisms and $S h$. sonnei was isolated from only 37 of them.

In Table $\mathrm{V}$ the results of culture and the numbers of fluorescent organisms are given for the series of
TABLE IV

COMPARISON OF FLUORESCENT ANTIBODY TECHNIQUE WITH CULTURAL METHOD IN ROUTINE SPECIMENS

Results of Culture Numbers of Fluorescing Organisms

t+t+t+t+t+t 0 Total

\begin{tabular}{lcccccc}
\hline $\begin{array}{l}\text { Shigella sonnei } \\
\text { positive }\end{array}$ & 18 & 15 & 17 & 20 & 51 & 121 \\
$\begin{array}{l}\text { Shigella sonnei } \\
\text { negative }\end{array}$ & 4 & 4 & 14 & 20 & 157 & 199 \\
& & & & & & 320
\end{tabular}

$\left.\begin{array}{rll}++++ & = & >20 \\ +++ & =11-20 \\ ++ & =1-10 \\ + & =<1 \\ 0 & =0\end{array}\right\}$ organisms per field

TABLE V

COMPARISON OF FLUORESCENT ANTIBODY TECHNIQUE WITH CULTURAL METHOD IN CASES OF DIARRHOEA

Results of Culture Numbers of Fluorescing Organisms

+++++++++0 Total

Shigella sonnei

positive

Shigella sonnei

negative

$\begin{array}{llllll}20 & 0 & 6 & 3 & 7 & 36\end{array}$

$++t=>20$

$++t=11-20$

$++=1-10$ organisms per field

+1
$0=0$

$\begin{array}{llllll}0 & 0 & 2 & 7 & 29 & 38\end{array}$

cases of diarrhoea. Sh. sonnei was isolated from all of the 20 specimens in which there were large numbers $(+++$ and ++++$)$ of fluorescing organisms but from only nine of the $\mathbf{1 8}$ specimens in which smaller numbers $(+$ and ++$)$ were seen.

FALSE POSITIVE RESULTS The cause of the false $\stackrel{\mathbb{D}}{+}$ positive results was investigated in some detail.

It was thought that one possible explanation might be that some of the fluorescing organisms in false positive specimens were dead Sh. sonnei. A comparison of the results from two groups of persons whose specimens were negative by culture but 
TABLE VI

COMPARISON OF FLUORESCENT ANTIBODY TECHNIQUE WITH CULTURAL METHOD

\begin{tabular}{|c|c|c|c|c|c|c|c|c|}
\hline \multicolumn{3}{|c|}{ Results of Culture } & \multicolumn{6}{|c|}{ Numbers of Fluorescing Organisms } \\
\hline & & & ++++ & +++ & ++ & + & $\mathbf{0}$ & Total \\
\hline \multirow{2}{*}{\multicolumn{3}{|c|}{$\begin{array}{l}\text { Shigella sonnei } \\
\text { negative in contacts and convalescent cases } \\
\text { Shigella sonnei } \\
\text { negative in persons with no known contact with Sonne dysentery }\end{array}$}} & 3 & 2 & 6 & 8 & 71 & 90 \\
\hline & & & 1 & 2 & 8 & 12 & 86 & $\begin{array}{l}109 \\
199\end{array}$ \\
\hline \multicolumn{2}{|c|}{$\begin{aligned}+++ & =>20 \\
+++ & =11-20 \\
++ & =1-10 \\
+ & =<1 \\
0 & =0\end{aligned}$} & organisms per field & & & & & & \\
\hline
\end{tabular}

positive by fluorescence microscopy was therefore made. One group consisted of convalescent cases and healthy contacts of cases of Sonne dysentery; the other group consisted of persons not known to have suffered from Sonne dysentery and without any known contact with a patient. Results of this comparison are shown in Table VI.

On the figures available, the difference between the two groups could easily be explained by chance, but the possibility remains that a proportion of the false positive results may be caused by dead organisms.

Ten specimens giving false positive results were cultured on (1) blood agar, (2) MacConkey agar, (3) deoxycholate citrate agar, (4) blood tellurite agar, (5) tomato agar (incubated aerobically and anaerobically), (6) meat broth (subcultured on blood agar and incubated aerobically and anaerobically), and (7) Sabouraud's agar. Numerous individual colonies were picked off each of these media and tested by the fluorescence technique, but it was not possible to isolate in culture the same kind of organisms which were seen to fluoresce by direct microscopy of the specimens.

Seven fresh specimens of faeces, negative by culture, were kept at room temperature and examined by the fluorescence technique at intervals over a period of a week to see if staleness might be a cause of false positive results. Six of these specimens were consistently negative, but one gave the following results: First day negative, second day positive ( $<1$ fluorescent organism per field), third day negative, seventh day positive $(<1$ fluorescent organism per field). It therefore seems unlikely that keeping specimens at room temperature for 24 to 48 hours before fluorescence microscopy is a significant cause of false positive results.

One hundred and sixty-two specimens were tested with Sh. sonnei phase 1 and phase 2 conjugates separately as well as mixed. Of $\mathbf{4 6}$ specimens in this series positive by culture and in which were found organisms that fluoresced with the mixture of phase 1 and phase 2 conjugates, 44 were fluorescent positive with phase 1 conjugate alone and 21 with phase 2 conjugate alone. On the other hand, of 20 specimens negative by culture, but in which were found organisms that fluoresced with the mixture of phase 1 and phase 2 conjugates, 16 were fluorescent positive with phase 1 conjugate alone and 15 with phase 2 conjugate alone. In other words, with phase 1 conjugate alone, 2/46 'true positives' detected by the mixture would have been missed but $4 / 20$ false positives avoided; with phase 2 conjugate alone, $25 / 46$ true positives detected by the mixture would have been missed and 5/20 false positives avoided.

Portions of phase 1 and phase 2 conjugates were absorbed with their homologous strains of $S h$. sonnei. The conjugates thus absorbed were mixed and used in the same way as the unabsorbed conjugates had been used previously. On testing falsepositive specimens with the absorbed conjugates, it was found that these specimens no longer showed fluorescent organisms. It seems that the organisms which had fluoresced with the unabsorbed conjugates had a surface antigen to which there was an antibody present in the conjugate, and that this antibody was absorbed out by the homologous strains of Sh. sonnei used for preparing the antisera. It would appear, therefore, that at least some of the organisms responsible for false positive results may have been dead organisms of an unknown kind which reacted specifically with the conjugates.

Treating smears of false positive specimens with normal rabbit serum before applying the fluorescent conjugate failed to prevent fluorescence, suggesting that false positive results were not caused nonspecifically by some component of normal rabbit serum which might have conjugated with fluorescein.

\section{DISCUSSION}

In this comparison of culture and fluorescence microscopy for the detection of Sh. sonnei in faeces, the results obtained by the two methods have been 
in agreement in $285(73 \%)$ of the 394 specimens of faeces examined. It is not surprising that the cultural method, which has been estimated to be capable of demonstrating the presence of Sh. sonnei when this organism is present in faeces in numbers less than 10,000 per g., should reveal some positive results when the microscopic method, whose limit of sensitivity was of the order of $1,000,000$ per g., gave negative results. This combination of results was observed in 57 of the 155 specimens of faeces from which Sh. sonnei was isolated.

In the two series, 52 specimens of faeces gave a positive result by fluorescence microscopy but Sh. sonnei was not isolated on culture. Although Sh. sonnei was isolated by a subsequent culture from one of these specimens, it seems probable that most of these must represent false positive results by the fluorescence technique. One possible explanation of this phenomenon might be that the faeces contained dead Sh. sonnei. If this were so, one would expect this finding to occur more often in persons who were contacts of, or convalescent from, Sonne dysentery. In fact, these false positive results were observed equally, whether or not there was any history of infection or contact with Sonne dysentery.

Another possible explanation is that there were organisms in the faeces, having some or all of the antigens of Sh. sonnei, which reacted with the fluorescent antiserum and gave a positive microscopic result. A number of these specimens was cultured on non-inhibitory media and an intensive but unsuccessful search made for colonies that reacted with the fluorescent antiserum. No explanation of these false positive results could be found but it was clear that when only small numbers of fluorescing organisms were seen, the specimen was more often negative by culture than when there were large numbers in the microscopic preparation.

Cherry et al. (1960) examined faecal smears from 291 patients with labelled antibody for Sh. sonnei. Twelve specimens showed fluorescent organisms, but Sh. sonnei was isolated in culture from only 10 of them. From an additional six specimens Sh. sonnei was isolated also, but all of these were negative by their fluorescence technique.
The great benefit of fluorescence microscopy as $\stackrel{0}{\tilde{\sigma}}$ presumptive positive result can be obtained. The $\vec{F}$ method can, therefore, be employed with advantage in outbreaks of diarrhoea, for if specimens from $\frac{}{2}$ several persons are examined and are found to $\frac{\bar{\omega}}{\bar{\omega}}$ contain large numbers of fluorescing organisms, $a \frac{\vec{\phi}}{\sigma}$ presumptive diagnosis of Sonne dysentery can be $\propto$ established within one hour. In fact, in an outbreak $\%$ of diarrhoea in a boarding school, specimens from $\overrightarrow{0}$ 19 cases were examined by the fluorescent antibody $\rightarrow$ technique. In all of them large numbers of fluorescent $\vec{\omega}$ organisms were seen, and these results were con- $\frac{2}{8}$ firmed by culture.

However, in our hands, the fluorescent antibody $\vec{v}$ technique described was not sufficiently reliable for $\omega$ the examination of specimens from sporadic cases, $N$ whether from patients with diarrhoea, from contacts of cases of Sonne dysentery, or from persons 5 convalescent from Sonne dysentery.

We are grateful to Dr. K. Patricia Carpenter, Director of the Dysentery Reference Laboratory, Colindale, and to $\vec{\odot}$ Dr. M. T. Parker, Director of the Cross-Infection ${ }^{+}$ Reference Laboratory, Colindale, for constructive 0 criticism in the course of this work.

\section{REFERENCES}

Biegeleisen, J. Z. Jr., Scott, L. V., and Lewis, V. Jr. (1959). Science, $129,640$.

Carver, R. K., and Goldman, M. (1959). Amer. J. clin. Path., 32, 159.

Cherry, W. B., Goldman, M., and Carski, T. R. (1960). Fluorescent Antibody Techniques in the Diagnosis of Communicable Diseases. U.S. Public Health Service Publ. No. 729. U.S. Govt. Printing Office, Washington, D.C.

-, Thomason, B. M., Pomales-Lebrón, A., and Ewing, W. H. (1961). Bull. Wld Hlth Org., 25, 159.

Goldstein, G., Slizys, I. S., and Chase, M. W. (1961). J. exp. Med., O $114,89$.

Gordon, M. A. (1958). Proc. Soc. exp. Biol. (N.Y.), 97, 694.

Kalter, S. S., Hatch, M. H., and Ajello, G. W. (1959). Bact. Proc., 89. Liu, C. (1956). Proc. Soc. exp. Biol. (N.Y.), 92, 883. McEntegart, M. G., Chadwick, C. S., and Nairn, R. C. (1958). O
Brit.J. vener. Dis., 34, 1.

Metzger, J. F., and Smith, C. W. (1960). U.S. armed Forces med. J., D 11,1185 .

Moody, M. D., and Winter, C. C. (1959). J. infect. Dis., 104, 288.

Rinderknecht, H. (1960). Experientia (Basel), 16, 430.

Rodriguez, J., and Deinhardt, F. (1960). Virology, 12, 316.

Smith, C. W., Metzger, H. F., and Hoggan, M. D. (1962). Amer. J. N clin. Path., 38, 26. 